\title{
Communication problems facing nursing staff during their interaction with hospitalized mentally ill patients.
}

\author{
Walaa Saber Abd Elaziz, Bachelor of Nursing \\ Faculty of Nursing, Tanta University \\ Mervat Hosney,shalaby: Assistant professor of Psychiatric and Mental Health Nursing, \\ Faculty of Nursing, Tanta University \\ Zebeda Abd El Gawad Elsherif: lecturer of Psychiatric and Mental Health Nursing, \\ Faculty of Nursing, Tanta University
}

\begin{abstract}
Good communication between nurses and patients is essential for the successful outcome of individualized nursing care of each patient. Psychiatric nurses have been criticized for their lack of interaction and therapeutic engagement with patients. Many variables within the psychiatric setting affect communication. For example, factors related to the individual nurse, environment, patient and organization. This study aimed to assess communication problems that face nursing staff during their interaction with hospitalized mentally ill patients in psychiatric hospitals. The study was conducted in Tanta Mental Health Hospital which is affiliated to Ministry of Health \& population. The study subjects include all nurses working in Tanta Mental Health Hospital (80) of both sexes. Two tools were used by the researcher to collect the necessary data. Tool (1) Factors that hinder effective communication between nurses \& patients, structured questionnaire, and Tool (2) Nurses communication skills observational sheet. The main results revealed that all nursing staff are facing problems during their interaction with hospitalized mentally ill patients in psychiatric hospital, it was found that $70 \%$ of nurses reported that the failure to clarify roles and responsibilities of each member of the team always hinder communication, and also three- quarters of nurses $(75.1 \%)$ reported that too much papers work and waste of time always hinder communication, It was obvious that more than half of the sample $63.3 \%$ reported that patients who are slow in response always hinder communication, $67.6 \%$ reported that the aggressive behaviors of patients always hinder communication, It was concluded that all nursing staff face problems during their interaction with hospitalized mentally ill patients in psychiatric hospitals but with varying degrees. Also, all nursing staff experience difficulties in communication skills but with varying degrees, so it was recommended that nurse communicators need support in order to be effective. Training programs are needed for hospital staff about effective communication to improve their interaction with patients.
\end{abstract}

Key terms; communication, problems, nurses, mentally ill patient

\section{Introduction}

Mental health nurses operate in an interpersonal context and at the center of this is nurse-patient communication. The ability to establish therapeutic communication with patient is one of the most important skills a nurse can develop. In spite of its importance in 
all nursing specialties, the therapeutic communication is especially crucial to the success of intervention with patient requiring psychiatric care. ${ }^{(1,2)}$ If the nurse - patient communication develops well, it can play a large part in sustaining the patient in the face of emotional difficulties, bring about insight and behavior change in them. ${ }^{(3)}$

Accordingly communication can be defined as dynamic information-sharing process that occurs between people and their environment. Communication occurs between and among all people in all situations and circumstances of life. It occurs between family members, friends, and colleagues, as well as between nurses and clients. so communication is an essential tool of psychiatric nurses. ${ }^{(1.4)}$ Moreover communication is a complex process that consists of a combination of verbal and nonverbal behaviors used in various ways to share information. Communication therefore requires much practice in order to be effective. ${ }^{(5)}$

Competent communications enhance patient satisfaction, health outcome, and adherence to treatment. Learning communication skills enable nurses to break bad news in a way that is less uncomfortable for them and more satisfying for the patient. Certain studies stated that, communication is the true answer to make appropriate connection with the patient and establish their trust. ${ }^{(6)}$ The Joint Commission Association Health Organization ( JCAHO ) emphasizes that poor nurse - patient communication can affect patient safety and feeling, noting that the nurse is an important source of information which can avoid potential adverse effects and hazardous consequence in patient condition. Furthermore, breakdowns in communication between nurse and patient have been shown to be a factor in malpractice litigation. ${ }^{(7)}$ For these reasons, nurses need to understand and master the general principles of communication especially the psychiatric nurses for whom the therapeutic communication is the primary tool for working effectively with patient. This enables psychiatric nurses to meet standards of care and perform their role. ${ }^{(8)}$

Providing appropriate communication with the patients is one of the necessary tools for nurses in psychiatry wards, which is useful in management of the patients with psychiatric disorders. ${ }^{(9)}$. Some important reasons for inappropriate relationship between the nurse and patient can be lack of necessary skills to communicate with patients because of insufficient training. $(10,11)$

In a certain studies on the factors of effective communication of the nurses with the hospitalized psychiatric patients, it was demonstrated that the ability to understand the patient; empathize with him/her; appropriately communicate with him/her has a deep effect on the bilateral relationship of nurses and patients in emergency psychiatry wards. ${ }^{(12)}$

The quality of the interactions and the ability to improve it is frequently governed by diverse factors including the nurse's attitude, his or her ability to understand behavior within a social context, and his or her openness to listening and responding empathetically to others. Research of ( Cooper et al;2003) indicates that quality communication among the patient, health care providers, families, and other stakeholders can improve health care and help patient adapt to illness and adhere to interventions. ${ }^{(13)}$

Many factors have been reported as influencing effective communication in healthcare. These include individual abilities and characteristics, team behaviors and systemic factors and the lack of organizational support of a culture safety. In addition, it has been suggested that improving communication requires a detailed understanding of the setting and context in which patient care is delivered and a commitment on behalf of a healthcare organization to a culture of safety and quality improvement, such as supporting team-based delivery of 
care. Sustainable improvements towards effective communication in healthcare settings involve synchronizing efforts across the three levels that is, the individual, the team and the organization. ${ }^{(14)}$

In addition certain obstacles occur in the nurse-patient relationship that affects the nature of the communication. These obstacles are due to the patient's disorder or lack of knowledge, and the nurse's own inability to be effective because of inexperience, or personal problems for the relationship to grow in a healthy manner. ${ }^{(15)}$ Nurses entering psychiatric-mental health settings bring with them values, beliefs and perspectives that influence their interactions with patients. At the same time, these patients usually have intense emotions and complex behaviors, their care can pose unique challenges for nurses to control their own emotional reactions and check their social biases. ${ }^{(16)}$

Attitudes and behaviors that may block effective interaction with patients experiencing mental health problems include judgmental attitudes, excessive probing, and lack of selfawareness. Nurses need to approach each patient with unbiased perspectives, and during discussions, nurses need to make sure to remain focused on essential problems and avoid explorations unrelated to the issue or challenge of concern. Additionally, nurses must be able to monitor and contain their own responses when patients discuss frightening incidents or relate tragedies that generate feelings of hopelessness, despair, anxiety, disgust, fear, anger, or distress. $^{(15,16)}$

Nurses must also understand the role that culture plays "in professional communication, experienced nurses are aware that trancultural differences may create barriers to verbal and nonverbal communication that in turn, can negatively affect patient outcomes by recognizing that these barriers may exist and continually striving for cultural competence, nurses can increase the likelihood of effective communication with individuals who identify with another culture or ethnic group. ${ }^{(17)}$

Fakhoury and Wright (2008) carried out various studies on physical harms of the therapists working in psychiatry centers, and stated that the nurses who have lower scientific and professional competence and do not have adequate knowledge about how to deal with and provide an appropriate relationship with psychiatric patients are more susceptible. ${ }^{(18)}$ An important reason of inappropriate nurse-patient communication is the insufficient skill of the nurse in providing the relationship, because of the inadequate education. ${ }^{(19)}$ Although communication skill training is an important part of education in medicine and Para-medicine fields, it was demonstrated that the theoretical communication skills cannot necessarily be used in clinical settings, and education in clinical fields is also necessary. ${ }^{(20)}$

\section{Aim of the study}

To assess communication problems that face nursing staff during their interaction with hospitalized mentally ill patients in psychiatric hospitals.

\section{Research question}

What are the communication problems that face nursing staff during their interaction with hospitalized mentally ill patients in psychiatric hospitals?

\section{Materials \& Method}

Materials

Research Design 
The present study follows a descriptive research design.

\section{Setting-:}

The study was conducted at Tanta Mental Health Hospital which is affiliated to the Ministry of Health and population with a capacity of 107 beds, divided into four wards, two wards for male patients and two wards for female patients. This hospital serves three governorates; namely, El-Gharbeya, ElMenofeya, and Kafr-El-Sheikh.

\section{Subjects-:}

The study subjects include all available nurses working at Tanta Mental Health Hospital (80 nurses) of both sexes who have the following inclusion criteria:

- Nurses who provide a direct care to hospitalized patients.

- Nurses who agree to participate in the study.

\section{Tools of the study}

The data of this study were collected using the following tools;

Tool (1) Factors that hinder effective communication between nurse \& patient questionnaire, It consists of two parts-:

Part (1) includes: Socio-demographic and occupational data questionnaire for psychiatric nurses. It was developed by the researcher to elicit data about the nurse such as, age, sex, marital status, level of education and occupation. Occupational data, which include, department, years of experience, pervious training in mental health hospital...etc.

Part (2): Factors that hinder effective nurse- patient Communication questionnaire; It was developed by the researchers after review of recent literature to determine factors that hinder communication between nurses \& patients. It consists of 66 items instrument distributed over 4 subscales. These subscales include:

1- Patient related factors involve 14 items such as slow patient response, aggressive behavior on part of patient and the patient symptoms such as delusions and hallucinations

2- Physical environmental factors. This involves 11 items, such as the presence of noise, unclean environment and poor ventilation.

3- Organization environmental factors that hinder nurse's communication this involves 30 items divided into;

a- 13 items related to work with colleagues such as frequent attribution of inventory to nurse from other colleagues, shortage of nurses ,increased work load and lack of support from colleagues.

b- 17 items related to hospital management and work with supervisors such as large efforts award to them cause stress, suffer from a lack of information and skills to work with enthusiasm and too much papers to work and waste of time that hinder communication with patient.

4- Nurses ' s related factors that hinder them to communicate with patients this involves 11 items such as their work in the psychiatric hospital causes them embarrassment with family and society. Nurse's negative attitudes and beliefs about mental illness and their feeling of lack of self confidence and self-esteem.

Scoring system of Factors that hinder effective nurse- patient communication was classified as follows: Each item is scored on a 3-point Likert scale from 1(never) to 3(always) It has been changed from a 5-point Likert scale to a 3-point Likert scale according to statistical experts. Each nurse can receive a score ranging from 66 to 198 points. Evaluation of this questionnaire was as follows.

$<50 \%$ means weak factor

$50-75 \%$ means moderate factors

$>75 \%$ means strong factors 
Tool (2) Nurses' communication skills observational sheet, It was developed by BayerFetzer Group in (2011) ${ }^{(21)}$ to determine nurse's communication skills with patient. It consists of 36 items distributed in 7 sub scales:

1-Building a relationship with patient. It involves 4 items such as greeting and showing interest in patient as a person and using words that show care and concern throughout the warm \& professional interview.

2-Openning discussion with patient. It involves 3 items such as allowing patient to complete opening statement without interruption.

3-Gathering information from patient. It involves 11 items such as clarifying details as necessary with more specific, summarizing and giving patient an opportunity to correct or add information and communicate using good non-verbal and verbal techniques.

4-Understanding the patient. It involves 5 items such as asking about life events, circumstances and supporting and encouraging patient to benefit from his special abilities and capacities.

5-Sharing information with patient. It involves 4 items such as assessing patient understands of problem and desire for more information and explaining using words that patient can understand / using educational aid.

6-Reaching agreement with patient. It involves 4 items such as includes patient in choices and decisions to the extent he/she desires and checking for a mutual understanding of diagnostic and/or treatment plan.

7-Providing closure with patient. It involves 5 items such as asking if the patient has questions, concerns or other issues and discussing / clarifying follow-up or contact arrangements.

Scoring system of Nurses' communication skills observational sheet was done as follows; each item is scored on a 5-point Likert scale from 1(poor) to 5(excellent).

Each nurse can receive a score ranging from 36 to 180 points. Evaluation of this observational sheet will be as follows;

1- From 36 to 90 indicated poor communication skills.

2-From 91 to108 indicated fair communication skills.

3-From109 to 135 indicated good communication skills.

4-From 136 to153 indicated very good communication skills.

5-From 154 to180 indicated excellent communication skills.

\section{Methods;}

\section{The study was accomplished according to the following steps;}

-A written official letter from the Faculty of Nursing, Tanat University was directed to the director of Tanta Mental Health Hospital to take their permission to collect data after explaining the goal of the study and the way of data collection.

- Informed consent obtained from every nurse after explaining the purpose of the study.

-Informing study subjects that confidentiality and privacy of any obtained information will be ensured. Respecting the right of the study subject to withdraw from the study at any time.

-Tool (1) was developed by the researcher after review of recent literature.

-Tool (2) was translated into Arabic language by the researchers and was tested for translation.

-Tools $(1 \& 2)$ were presented to a Jury composed of five experts, in the psychiatric nursing fields and Nursing services administration fields to ensure its content and validity. It was valid and required modifications were done.

-Tools' reliability was checked by Cronbch's alpha test and the result was highly reliable 
(0.929) (0.761). It was done on 8 nurses

-A pilot study was carried out before embarking in the field of work to ascertain clarity and applicability of the study tools and to identify obstacles that may be faced during data collection. It was carried out on 10 nurses according to inclusion criteria. They were selected randomly from the hospital ward after obtaining their written consent to participate in the study. After its implementation and according to the result of the pilot study, the statements are suitable to ensure understanding of the studied nurses. The pilot study subjects were later excluded from the actual study.

\section{Actual Study;}

- A written consent was obtained from each selected nurse according to the previous criteria for participation in the study after explaining the aim of the study, establishing rapport and trusting relationship with the studied nurses.

- Tool one Factors that hinder effective nurse- patient Communication questionnaire; It was implemented on an individual basis. And was implemented by the researcher using the interview questionnaire sheet to determine the factors hindering communication between nurse and patient regarding the following;

1- Patient related factor that hinder nurses to communicate with patients, such as slow to speak, repeat talking in one subject, speechless uneven, stutter speaks, reply with inappropriate answer to the question.

2-Physical environmental factor that hinder nurses to communicate with patient, such as the presence of noise, the environment unclean, poor ventilation, insufficient and inappropriate lighting, sitting in uncomfortable places for the patient, the temperature of the place is not appropriate

3- Organizational environmental factor that hindering nurses to communicate with patient, such as nurse's success at work lead to problems with other colleagues and is reflected negatively on the communication with the patient, frequent attribution of the inventory to nurses from other colleagues leads to stress and affects communication with the patient and work load awarded to nurse leads to stress which affects their communication with the patient.

4- Nurses' problem, such as nurses who work in the Psychiatric Hospital are embarrassed with family and society which affects nurse's connection with the patient.

- Tool two Nurse's communication skills observational sheet, the researcher observed nurses while communicating with patient regarding the following:

\section{I- Building a therapeutic Relationship such as;}

Greeting and showing interest in patient as a person, using words that showing care and concern throughout the warm \& professional interview.

\section{II: Opening the Discussion}

Allowing patient to complete opening statement without interruption, asking "Is there anything else? To elicit full set of concerns.

\section{III- Gathering information from patient}

Begins with patient's story using open-ended questions, clarifying details as necessary with more specific, use of "yes/no" questions.

IV Understanding the Patient's Perspective

Asking about life events, circumstances, asking about other people that might affect patient health.

\section{V-Sharing information with patient}

Assessing patient's understanding of problem and desire for more information. Explaining using words that patient can understand / using educational aid. 


\section{VI: Reaching Agreement (new / changed plan)}

Includes patient in choices and decisions to the extent $\mathrm{s} / \mathrm{he}$ desires.

Checking for mutual understanding of diagnostic and/or treatment plans.

\section{VII: Providing Closure}

Asking if patient has questions, concerns or other issues. Summarizing, affirming agreement with plan of action.

- Each observation was implemented on an individual basis.

- Each observation lasted for about 20-30 minutes according to nurses' attention and willing to cooperate or talk with patient.

- Data were collected over a period of four months starting from September,2014 and ending in December, 2014.

\section{Statistical analysis:}

The collected data were organized, tabulated and statistically analyzed using SPSS version 19 (Statistical Package for Social Studies) created by IBM, Illinois, Chicago, USA. For numerical values the range, mean and standard deviations were calculated. The differences between two mean values were calculated using student's t test. For categorical variable the number and percentage were calculated. The relations between two variables were tested by Pearson's, correlation coefficient. The level of significance was adopted at $\mathrm{p}<0.05$.

\section{Limitations of the study;}

The study was conducted with only 80 psychiatric nurses working in a large state hospital. The small sample size limited the overall generalization of the findings to the greater population of Public Psychiatric Hospital.

\section{Results:}

Figure (1): Distribution of studied nurses by age groups in years. Regarding the range of nurses age years was 22-56 and the mean age was $32.03 \pm 9.33$ years. Less than half of nurses $(43.8 \%)$ aged 20 to less than 30 years and $(33.7 \%)$ of them aged 30 to less than 40 years and $8.7 \%$ aged more than 50

Figure (2) :Distribution of studied nurses in relation to their work, qualifications, and occupation of studied nurses. Regarding the place of work more than half of the sample (65\%) work in male ward. Concerning qualifications $41.3 \%$ had a technical institute of nursing while $18.8 \%$ had a bachelor degree of nursing. Regarding their occupation, the majority of the sample $80 \%$ was nurses while the $8.8 \%$ were head nurses.

Figure (3); Distribution of studied nurses in relation to their experience in general nursing and psychiatric care in years ; In relation to the experiences in general nursing indicate that more than half of the sample $51.3 \%$ had 1 to less than 5 years, while $15 \%$ of them had 10 to less than 15 years. However, the range of experience years in general nursing was 1-20 years, the mean of experience was $5.99 \pm 4.99$ years and the median was 4.0 years. In relation to experiences in psychiatric nursing it indicate that $38.7 \%$ of the sample had 1 to less than 5 years and $20 \%$ of them had more than 15 years, the range of experience years in psychiatric nursing was 1-30 years; the mean of experience was $8.61 \pm 7.05$ years and the median was 6.0 years.

Figure (4): Distribution of studied nurses by previous training; Regarding the previous training sessions in communication skills for nurses, $20 \%$ had attended one session and $23.8 \%$ had attended two sessions , $13.8 \%$ had attended three sessions , 21.3\% had attended 4 sessions, while $21.3 \%$ had not attended any session. 
Table (1):- Distribution of the studied nurses by patient related factor hindering nursing- patient communication. It was obvious that more than half of the sample $63.3 \%$ reported that patients who are slow in response strongly hinder communication, while $35 \%$ reported that this had moderate effect. Only $1.3 \%$ reported that they weakly hinder communication. More than half of nurses $67.6 \%$ reported that the aggressive behaviors of patients strongly hinder communication, while $30.1 \%$ reported that this had moderate effect, compared to a minority $1.3 \%$ reported that they weakly hinder communication. More than half of nurses $52.6 \%$ reported that the patient suffering from delusions and hallucinations had moderately hinder communication, while $40 \%$ reported that they are strongly hinder communication. However, $7.5 \%$ reported that they weakly hinder communication.

Table (2):- Distribution of the studied nurses by factors of co-workers hindering nursing- patient communication. It was found that more than half of nurse's $61.3 \%$ reported that frequent attribution of inventory to them from other colleagues strongly hinder communication, while $10 \%$ reported that this weakly hinder communication. Also, $68.8 \%$ reported that the shortage of nurses and the increased work load strongly hinder communication, while $23.8 \%$ reported that this had a moderate effect, compared to $7.5 \%$ who reported that this weakly hinder communication. More than half of nurses $58.8 \%$ reported that non-parity or justice in distributing the incentives strongly hinder communication, while $26.3 \%$ reported that this had a moderate effect. Only $15 \%$ reported that this weakly hinder communication.

Table (3):- Distribution of the studied nurses by hospital management and work with supervisors factors hindering nursing- patient communication. It was found that $70 \%$ of nurses reported that the failure to clarify roles and responsibilities of each member of the team strongly hinder communication, while $23.8 \%$ reported that this had a moderate effect. Only $6.3 \%$ reported that this weakly hinder communication. More than threequarters of nurses $75.1 \%$ reported that too much papers and waste of time strongly hinder communication, while $17.6 \%$ reported that this had a moderate effect. However, $6.3 \%$ reported that this weakly hinder communication. More than two thirds of nurses $70 \%$ reported that deficit in all possibilities for action strongly hinder communication, while $25 \%$ reported that this had a moderate effect and 5\% reported that this weakly hinder communication.

Table (4) illustrates Distribution of the studied nurses by physical environmental factors that hindering nursing- patient communication. It was noticed that the majority of nurses $83.8 \%$ reported that the presence of noise strongly hinder communication, while $15 \%$ reported that this is had a moderate effect and $1.3 \%$ reported that they weakly hinder communication. Around $85 \%$ reported that unstructured location strongly hinder communication, while $12.5 \%$ of those reported that this is had a moderate effect, compared to $2.5 \%$ who reported that they weakly hinder communication. More than three- quarters of nurses $77.6 \%$ reported that the lack of privacy of the place strongly hindering communication, while $20.1 \%$ reported that this is had a moderate effect. However, $2.5 \%$ reported that this weakly hinder communication.

Table (5):-Shows Distribution of the studied nurses according to nurses's problems that hindering nursing- patient communication. It was obvious that more than half of nurses $56.3 \%$ reported that their work in the psychiatric hospital cause embarrassment with their family and society strongly hinder communication with patient, while $22.5 \%$ reported that this weakly hinder communication. More than half of nurses $60.1 \%$ reported that their negative attitudes and beliefs about mental illness strongly hinder communication with patient, while $40.1 \%$ reported that this is had a moderate effect. Also, more than half of nurses $58.8 \%$ reported that lack of information and skills in dealing with psychiatric patients had a moderate effect, while $15 \%$ reported that this is weakly hinder 
communication. Around 57.5\% reported that feeling the relationship between nurses and patient's is psychologically boring had a moderate effect, while $13.8 \%$ reported that this weakly hindering communication.

Table (6):- Correlation between both the nurse's age and duration of nurses' experience and the total score of hindering factors and observational nurses communication skills. It was found that a statistical significant difference between the nurse's age and the hindering factor such as co-workers related factors $(r=0.232 \&$ $\left.\mathrm{p}_{=} 0.039\right)$. The table also displays that a statistical significant difference was observed between the experience in nursing and the hindering factors such as patient related hindering factors $(\mathrm{r}=0.223 \& \mathrm{p}=0.047)$ and also the hospital management and work with supervisors hindering factors $(\mathrm{r}=0.235 \& \mathrm{p}=0.037)$. This table also shows the correlation between age and duration of nurses' experience in relation to nurse's observational communication skills. A statistical significant difference was observed between the nurse's age and providing closure $(\mathrm{r}=0.274 \& \mathrm{p}=0.014)$. The table also demonstrates that a statistical significant difference was observed between experience in psychiatric nursing and observational communication skills in gathering information $(r=0.228 \& p=0.042)$, sharing information with patients $(\mathrm{r}=-0.243 \& \mathrm{p}=0.030)$, reach agreement $(\mathrm{r}=0.283 \& \mathrm{p}=$ $0.011)$ and providing closure $(\mathrm{r}=-0.257 \& \mathrm{p}=0.022)$.

Table (7):- Comparison between both the mean total score of hindering factors and observational nurse's communication skills in relation to the nurses' residence. No statistical significant difference was observed between hindering factors and nurses' residence such as patient related factors $(\mathrm{t}=0.138 \& \mathrm{p}=0.891)$. A statistical significant difference was observed between building therapeutic relationship and nurses' residence $(\mathrm{t}=2.254 \& \mathrm{p}=0.027)$.

Table (8):- Comparison between both the mean total score of hindering factors and observational nurse's communication skills in relation to nurses' gender. A statistical significant difference was observed between co-workers as a hindering factors and nurses' gender $(\mathrm{t}=3.016 \& \mathrm{p}=0.003)$, while a statistical significant difference was observed between hospital management and work with supervisors and nurses' gender $(\mathrm{t}=2.058 \& \mathrm{p}$ $=0.043$ ). The table also clarifies that a statistical significant difference was observed between observational communication skills in building therapeutic relationship ( $t$ $=4.337 \& \mathrm{p}=0.001)$, open the discussion $(\mathrm{t}=3.328 \& \mathrm{p}=0.001)$, gathering information $(\mathrm{t}=$ $3.018 \& \mathrm{p}=0.004)$, understanding patients' perspectives $(\mathrm{t}=2.736 \& \mathrm{p}=0.008)$, sharing information with patients $(\mathrm{t}=2.797 \& \mathrm{p}=0.008)$. Also a statistical significant difference was observed between reach agreement $(\mathrm{t}=2.718 \& \mathrm{p}=0.010)$, providing closure and nurses' gender $(\mathrm{t}=2.718 \& \mathrm{p}=0.010)$ respectively.

Figure (1): Distribution of studied nurses by age groups in years 


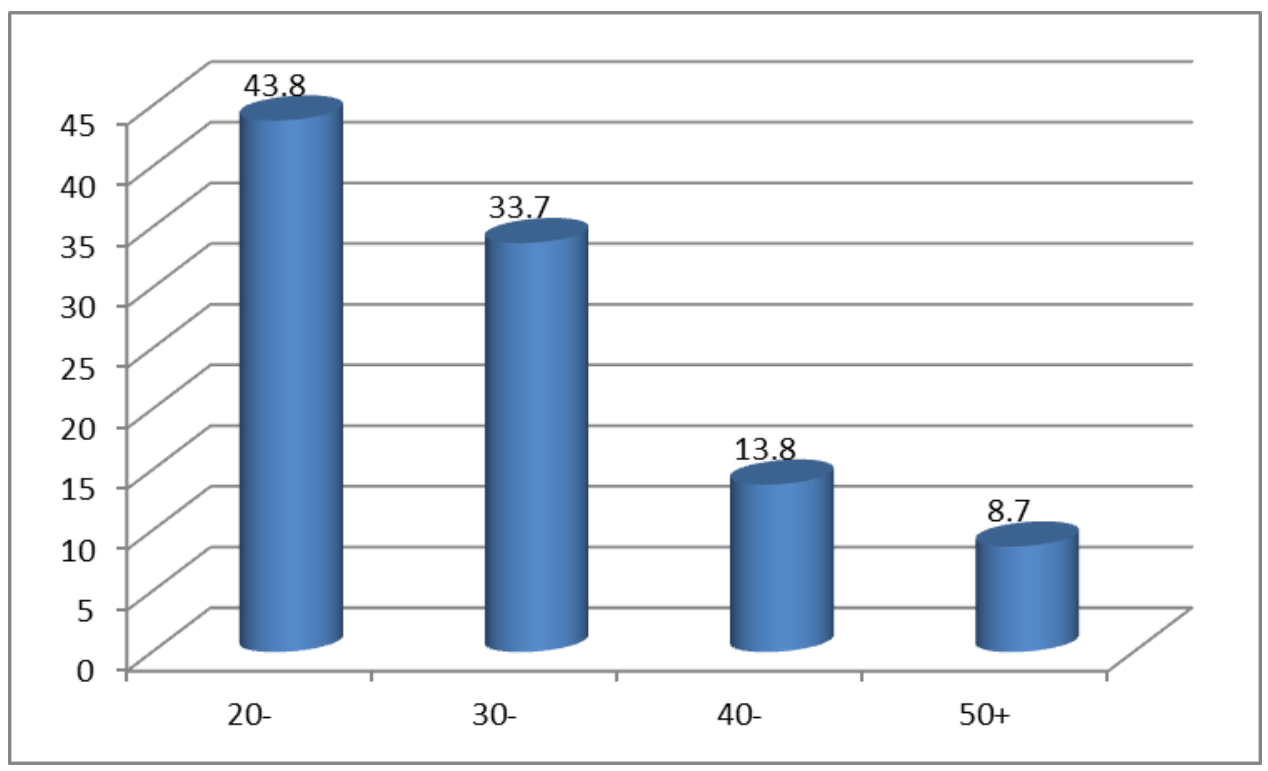

Figure (2 ) Distribution of studied nurses in relation to their work, qualifications, and job of studied nurses

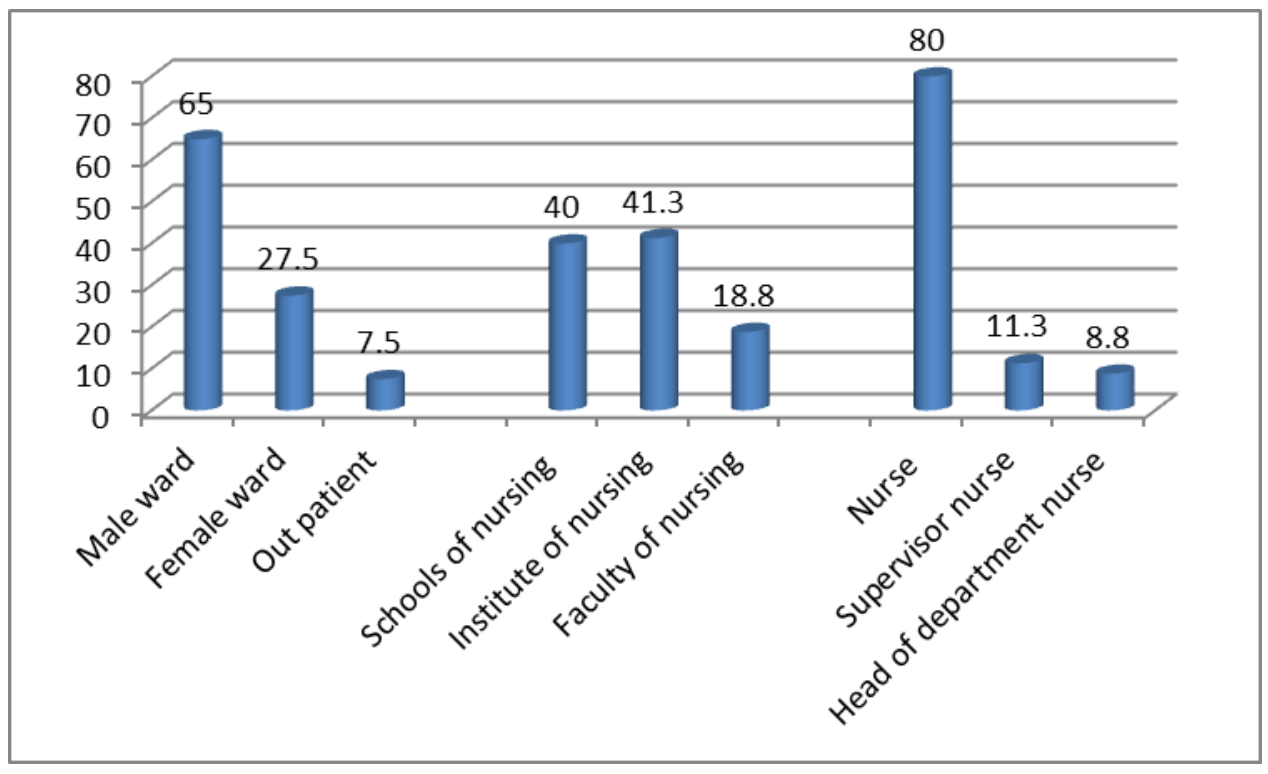

Figure (3): Distribution of studied nurses in relation to their experience in nursing and psychiatric care in years 


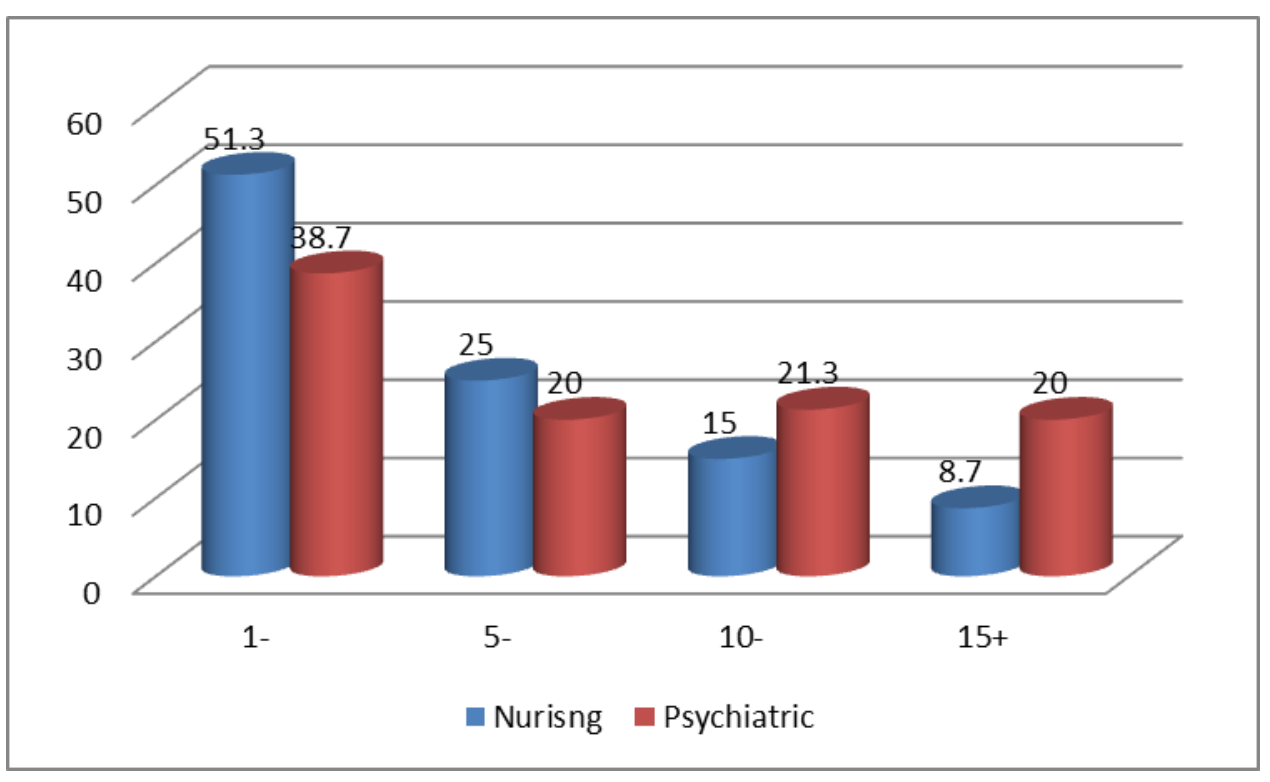

Figure (4): Distribution of studied nurses by previous training

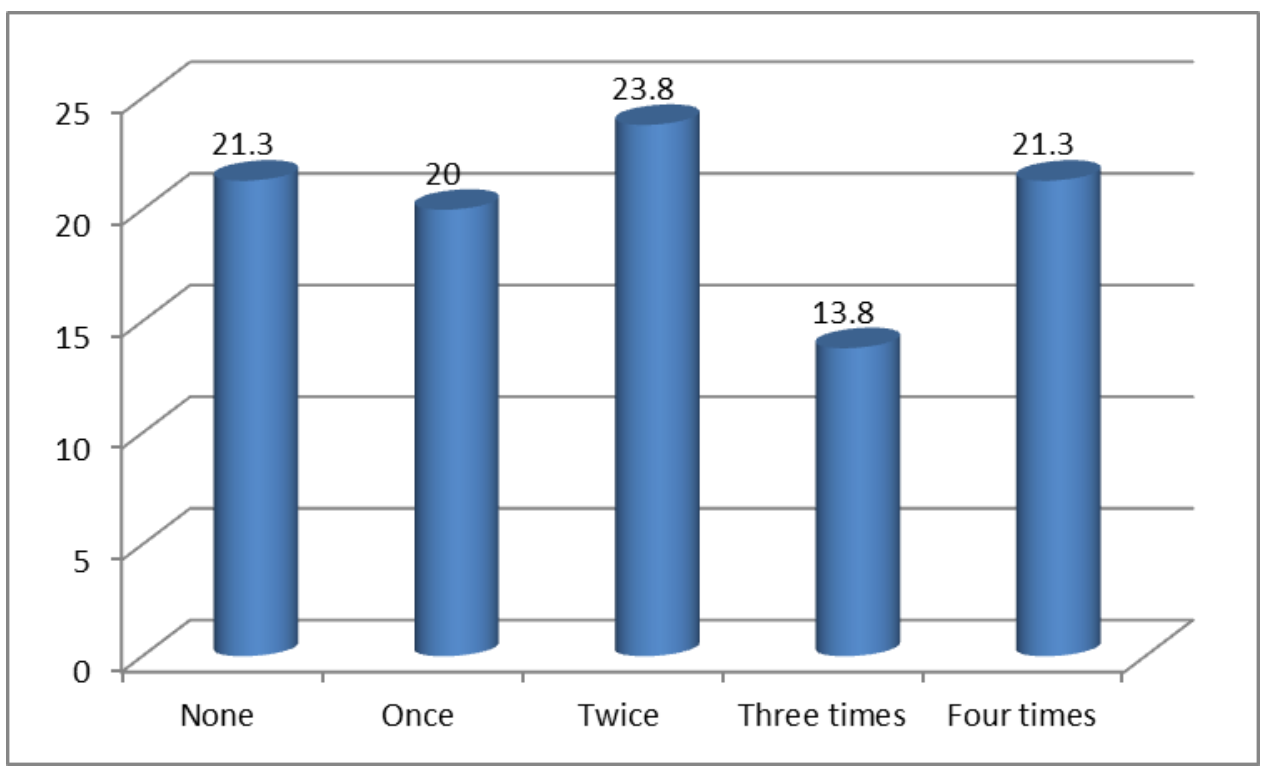

Table (1) Distribution of the studied nurses by patient related factor hindering nursing- patient communication. Number $(n=80)$

\begin{tabular}{|l|l|l|l|l|l|l|}
\hline \multirow{2}{*}{ Patient related causes } & Weak & \multicolumn{2}{l|}{ Moderate } & \multicolumn{2}{l|}{ Strong } \\
\cline { 2 - 7 } & No & $\%$ & No & $\%$ & No & $\%$ \\
\hline 1-Slow to speak & 3 & 3.8 & 48 & 60 & 29 & 36.3 \\
\hline 2-Slow response & 1 & 1.3 & 28 & 35 & 51 & 63.3 \\
\hline 3-Repeat talking in one subject & 2 & 2.5 & 28 & 35 & 50 & 62.5 \\
\hline
\end{tabular}




\begin{tabular}{|c|c|c|c|c|c|c|}
\hline 4-Speechless uneven & 2 & 2.5 & 28 & 35.1 & 50 & 62.6 \\
\hline 5-Stutter speak & 4 & 5.0 & 40 & 50 & 36 & 45.1 \\
\hline $\begin{array}{l}\text { 6-Replywith Inappropriate answer } \\
\text { to questions }\end{array}$ & 0 & 0.0 & 38 & 47.5 & 42 & 52.6 \\
\hline 7-Pause during speech & 4 & 5.0 & 34 & 42.6 & 42 & 52.6 \\
\hline 8-Aggressive behavior of patient & 2 & 2.5 & 24 & 30.1 & 54 & 67.6 \\
\hline 9-Inability to speak & 1 & 1.3 & 25 & 31.3 & 54 & 67.5 \\
\hline $\begin{array}{l}\text { 10-Inability to understand speech } \\
\text { playback }\end{array}$ & 2 & 2.5 & 35 & 43.8 & 43 & 53.8 \\
\hline 11-Inability to express in writing & 8 & 10.0 & 37 & 46.3 & 35 & 43.8 \\
\hline $\begin{array}{l}\text { 12-Lack of patient's insight into } \\
\text { the nature of his illness }\end{array}$ & 3 & 3.8 & 42 & 52.5 & 35 & 43.8 \\
\hline $\begin{array}{l}\text { 13- The patient suffers from } \\
\text { delusional and hallucinations }\end{array}$ & 6 & 7.5 & 42 & 52.6 & 32 & 40 \\
\hline $\begin{array}{l}\text { 14-Patient's escape from the } \\
\text { hospital and inclination to suicide }\end{array}$ & 5 & 6.3 & 18 & 22.5 & 57 & 71.3 \\
\hline
\end{tabular}


Table (2) Distribution of the studied nurses by factors of co-workers hindering nursing- patient communication. Number $(n=80)$.

\begin{tabular}{|l|l|l|l|l|l|l|}
\hline \multirow{2}{*}{ Coworkers related factors } & \multicolumn{2}{l}{ Weak } & \multicolumn{2}{l|}{ Moderate } & \multicolumn{2}{l|}{ Strong } \\
\cline { 2 - 7 } & No & $\%$ & No & $\%$ & No & $\%$ \\
\hline $\begin{array}{l}\text { 1-Your success at work cause you problems with } \\
\text { other colleagues }\end{array}$ & 21 & 26.3 & 39 & 48.8 & 20 & 25 \\
\hline 2-Personal problems & 19 & 23.8 & 39 & 48.8 & 22 & 27.6 \\
\hline $\begin{array}{l}\text { 3-Frequent attribution of inventory to you from other } \\
\text { colleagues }\end{array}$ & 8 & 10.0 & 23 & 28.8 & 49 & 61.3 \\
\hline 4-Shortage of nurses and the great efforts & 6 & 7.5 & 19 & 23.8 & 55 & 68.8 \\
\hline $\begin{array}{l}\text { 5-Not hearing and paying attention of co-workers to } \\
\text { your opinion }\end{array}$ & 7 & 8.8 & 35 & 43.8 & 38 & 47.6 \\
\hline $\begin{array}{l}\text { 6-There are conflicts and disagreements between } \\
\text { you and your co-workers }\end{array}$ & 18 & 22.5 & 41 & 51.3 & 21 & 26.3 \\
\hline 7-Inability to adjust your passivity with co-workers & 12 & 15.0 & 40 & 50.1 & 28 & 35 \\
\hline $\begin{array}{l}\text { 8-There is no support from your colleagues when } \\
\text { you face a problem with the patient }\end{array}$ & 12 & 15.0 & 48 & 60 & 20 & 25.1 \\
\hline $\begin{array}{l}\text { 9-Not accepting any criticism or suggestions from } \\
\text { your colleagues }\end{array}$ & 12 & 15.0 & 46 & 57.6 & 22 & 27.6 \\
\hline $\begin{array}{l}\text { 10-Individual differences between you and your } \\
\text { colleagues at work }\end{array}$ & 19 & 23.8 & 42 & 52.6 & 19 & 23.8 \\
\hline $\begin{array}{l}\text { 11-Non-parity or justice in distributing the } \\
\text { incentives }\end{array}$ & 12 & 15.0 & 21 & 26.3 & 47 & 58.8 \\
\hline $\begin{array}{l}\text { 12-Not convincing your colleagues work at the } \\
\text { psychiatric hospital at the beginning }\end{array}$ & 12 & 15.0 & 49 & 61.3 & 19 & 23.8 \\
\hline $\begin{array}{l}\text { 13-Thereis no collaboration between you and your } \\
\text { colleagues on performance and job tasks }\end{array}$ & 13 & 16.3 & 41 & 51.3 & 26 & 32.6 \\
\hline
\end{tabular}

Table (3 Distribution of the studied nurses by hospital management and work with supervisors factors hindering nursing- patient communication. Number $(n=80)$.

\begin{tabular}{|l|l|l|l|l|l|l|l|}
\hline \multirow{2}{*}{ Hospital management factors } & \multicolumn{2}{l|}{ Weak } & \multicolumn{2}{l|}{ Moderate } & \multicolumn{2}{l|}{ Strong } \\
\cline { 2 - 7 } & No & $\%$ & No & $\%$ & No & $\%$ \\
\hline $\begin{array}{l}\text { 1-Great effort in work cause you stress and affect your } \\
\text { communication with the patient. }\end{array}$ & 5 & 6.3 & 21 & 26.3 & 54 & 67.5 \\
\hline
\end{tabular}




\begin{tabular}{|c|c|c|c|c|c|c|}
\hline 2-Not participating in the adoption of decisions of the patient & 7 & 8.8 & 25 & 31.3 & 48 & 60.1 \\
\hline $\begin{array}{l}\text { 3-Failure to clarify roles and responsibilities of each Member } \\
\text { in the team. }\end{array}$ & 5 & 6.3 & 19 & 23.8 & 56 & 70 \\
\hline $\begin{array}{l}\text { 4-Suffer from a lack of information and skills to lead your } \\
\text { business with enthusiasm. }\end{array}$ & 9 & 11.3 & 26 & 32.6 & 45 & 56.3 \\
\hline $\begin{array}{l}\text { 5-Your boss never listens to you when you express your } \\
\text { opinion. }\end{array}$ & 9 & 11.3 & 34 & 42.5 & 37 & 46.3 \\
\hline $\begin{array}{l}\text { 6-Many papers to be filled from the administrative waste of } \\
\text { time. }\end{array}$ & 5 & 6.3 & 14 & 17.6 & 60 & 75.1 \\
\hline $\begin{array}{l}\text { 7-Your boss never accepts any information or new ideas } \\
\text { from you and reduce your communication with the patient. }\end{array}$ & 6 & 7.5 & 41 & 51.3 & 33 & 41.3 \\
\hline 8-Your business doesn't evaluate in an equitable manner. & 7 & 8.8 & 38 & 47.5 & 35 & 43.8 \\
\hline 9-You have a deficit in all possibilities for action. & 4 & 5.0 & 20 & 25 & 56 & 70 \\
\hline 10-Not trusting and praise you in working with the patient & 12 & 15.0 & 35 & 43.8 & 33 & 41.3 \\
\hline $\begin{array}{l}\text { 11-Your boss doesn't understand the problems you encounter } \\
\text { as you work with the patient and do not help you resolve. }\end{array}$ & 10 & 12.5 & 30 & 37.6 & 40 & 50 \\
\hline $\begin{array}{l}\text { 12-Not an encouraging and motivating of superiors to } \\
\text { achieve the required objectives. }\end{array}$ & 8 & 10.0 & 32 & 40.1 & 40 & 50 \\
\hline $\begin{array}{l}\text { 13-There are conflicts and disagreements with superiors at } \\
\text { work. }\end{array}$ & 11 & 13.8 & 37 & 46.3 & 32 & 40.1 \\
\hline $\begin{array}{l}\text { 14-Not allow for further University education and graduate } \\
\text { practitioners. }\end{array}$ & 9 & 11.3 & 41 & 51.3 & 30 & 37.5 \\
\hline 15-Do not take your opinion in scheduling work. & 8 & 10.0 & 16 & 20 & 56 & 70.1 \\
\hline 16-Discounts from money feel dissatisfaction. & 14 & 17.5 & 11 & 13.8 & 55 & 69 \\
\hline $\begin{array}{l}\text { 17- Failure to clarify relations between the functional roles of } \\
\text { each member in the team with others reflected negatively on } \\
\text { your communication with the patient. }\end{array}$ & 10 & 12.5 & 14 & 17.5 & 56 & 70.1 \\
\hline
\end{tabular}

Table (4) Distribution of the studied nurses by physical environmental factors that hindering nursing- patient communication. Number $(\mathrm{n}=80)$

\begin{tabular}{|l|l|l|l|l|l|l|}
\hline \multirow{2}{*}{ Physical Environmental factors } & \multicolumn{2}{l}{ Weak } & \multicolumn{2}{l|}{ Moderate } & \multicolumn{2}{l|}{ Strong } \\
\cline { 2 - 8 } & No & $\%$ & No & $\%$ & No & $\%$ \\
\hline 1-The presence of noise & 1 & 1.3 & 12 & 15.1 & 67 & 83.8 \\
\hline 2-The place is clean & 1 & 1.3 & 12 & 15.1 & 66 & 82.6 \\
\hline 3-Location of unstructured & 2 & 2.5 & 10 & 12.5 & 68 & 85 \\
\hline 4-Location of bad ventilation & 1 & 1.3 & 15 & 18.8 & 64 & 80.1 \\
\hline 5-Insufficient lighting and inappropriate & 2 & 2.5 & 18 & 22.6 & 60 & 75 \\
\hline $\begin{array}{l}\text { 6-Sitting in uncomfortable place for the patient } \\
\text { 7-The temperature of the place are not } \\
\text { appropriate }\end{array}$ & 3 & 3.8 & 33 & 41.3 & 44 & 55 \\
\hline 8-The presence of distracting stimuli & 1 & 1.3 & 26 & 32.6 & 53 & 66.3 \\
\hline 9-The lack of Privacy of the place & 2 & 2.5 & 16 & 20.1 & 62 & 77.6 \\
\hline
\end{tabular}




\begin{tabular}{|l|l|l|l|l|l|l|}
\hline $\begin{array}{l}\text { 10-The timing of the speech is not appropriate } \\
\text { in the place }\end{array}$ & 0 & 0.0 & 32 & 40 & 48 & 60.2 \\
\hline $\begin{array}{l}\text { 11-A number of inappropriate patients in the } \\
\text { room }\end{array}$ & 5 & 6.3 & 30 & 37.5 & 45 & 56.3 \\
\hline
\end{tabular}

Table (5): Distribution of the studied nurses according to nurses' $s$ problems that hindering nursing- patient communication. Number $(n=80)$.

\begin{tabular}{|c|c|c|c|c|c|c|}
\hline \multirow[b]{2}{*}{ Personal factors and nursing staff problems } & \multicolumn{2}{|c|}{ Weak } & \multicolumn{2}{|c|}{ Moderate } & \multicolumn{2}{|c|}{ Strong } \\
\hline & No & $\%$ & No & $\%$ & No & $\%$ \\
\hline $\begin{array}{l}\text { 1-Your work in the psychiatric hospital cause you } \\
\text { embarrassment with family and society }\end{array}$ & 18 & 22.5 & 17 & 21.3 & 45 & 56.3 \\
\hline $\begin{array}{l}\text { 2-Personality is characterized by sharpness that affect } \\
\text { the patient's psychological connection }\end{array}$ & 16 & 20.0 & 51 & 63.8 & 13 & 16.3 \\
\hline $\begin{array}{l}\text { 3-Inability to control emotions and concerns of patient } \\
\text { behavior }\end{array}$ & 9 & 11.3 & 53 & 66.3 & 18 & 22.5 \\
\hline $\begin{array}{l}\text { 4-Your style of dealing and communicating with } \\
\text { patients with mental disorders are not distinguished by } \\
\text { consistent }\end{array}$ & 17 & 21.3 & 49 & 61.3 & 14 & 17.5 \\
\hline $\begin{array}{l}\text { 5-Your negative attitudes and beliefs about mental } \\
\text { illness hindering communication with patient }\end{array}$ & 0 & 0.0 & 32 & 40.1 & 48 & 60.1 \\
\hline 6-Problems with family or career structure & 12 & 15.0 & 51 & 63.8 & 17 & 21.3 \\
\hline $\begin{array}{l}\text { 7-You do not have the ability to build a therapeutic } \\
\text { relationship with the patient and remedial } \\
\text { conservation }\end{array}$ & 17 & 21.3 & 47 & 58.8 & 16 & 20.1 \\
\hline 8-The fear of the patient's psychological problem & 11 & 13.8 & 50 & 62.5 & 19 & 23.8 \\
\hline
\end{tabular}




\begin{tabular}{|l|l|l|l|l|l|l|l|}
\hline 9-You feel lack of self confidence and Self-esteem & 12 & 15.0 & 50 & 62.5 & 18 & 22.5 \\
\hline $\begin{array}{l}\text { 10-Lack of information and skills in dealing with } \\
\text { patients with mental disorders }\end{array}$ & 12 & 15.0 & 47 & 58.8 & 21 & 26.3 \\
\hline $\begin{array}{l}\text { 11-Feel that the relationship between you and the } \\
\text { patient's psychological boring and has no-interest }\end{array}$ & 11 & 13.8 & 46 & 57.5 & 23 & 28.8 \\
\hline
\end{tabular}

Table (6) Correlation between both the nurse's age and duration of nurses' experience and the total score of hindering factors and observational nurse's communication skills

\begin{tabular}{|c|c|c|c|c|c|c|}
\hline \multirow[t]{2}{*}{ Variables } & \multicolumn{2}{|c|}{ Age in years } & \multicolumn{2}{|c|}{$\begin{array}{l}\text { Experience in } \\
\text { nursing }\end{array}$} & \multicolumn{2}{|c|}{$\begin{array}{l}\text { Experience in } \\
\text { psychiatric } \\
\text { nursing }\end{array}$} \\
\hline & $\mathrm{r}$ & $\mathrm{P}$ & $\mathrm{r}$ & $\mathrm{P}$ & $\mathrm{R}$ & $\mathrm{P}$ \\
\hline \multicolumn{7}{|l|}{ Hindering factors: } \\
\hline Patient related factors & -0.071 & 0.530 & -0.223 & $0.047 *$ & -0.146 & 0.195 \\
\hline Environmental related factors & 0.037 & 0.747 & -0.060 & 0.604 & 0.001 & 0.996 \\
\hline Co-workers related factors & 0.232 & $0.039 *$ & -0.114 & 0.314 & 0.195 & 0.083 \\
\hline $\begin{array}{l}\text { Hospital management and work with } \\
\text { supervisors }\end{array}$ & 0.026 & 0.821 & -0.235 & $0.037 *$ & 0.012 & 0.915 \\
\hline Nursing staff related factors & 0.032 & 0.775 & -0.161 & 0.153 & 0.032 & 0.775 \\
\hline \multicolumn{7}{|l|}{$\begin{array}{l}\text { Observational communication } \\
\text { skills: }\end{array}$} \\
\hline Building therapeutic relationship & -0.039 & 0.728 & 0.024 & 0.835 & -0.140 & 0.215 \\
\hline Open the discussion & 0.040 & 0.725 & 0.145 & 0.199 & -0.022 & 0.844 \\
\hline Gathering information & -0.171 & 0.130 & -0.069 & 0.544 & -0.228 & $0.042 *$ \\
\hline Understanding patients' perspectives & -0.058 & 0.608 & 0.069 & 0.543 & -0.131 & 0.245 \\
\hline Sharing information with patients & -0.162 & 0.150 & -0.063 & 0.578 & -0.243 & $0.030 *$ \\
\hline Reach agreement & -0.208 & 0.064 & -0.025 & 0.825 & -0.283 & $0.011 *$ \\
\hline Providing closure & -0.274 & $0.014^{*}$ & -0.006 & 0.957 & -0.257 & $0.022 *$ \\
\hline
\end{tabular}

*Significant at $\mathrm{p}$ - value $<0.05$.

R. correlation coefficient 
Table (7) Comparison between both the mean total score of hindering factors and observational nurse's communication skills in relation to the nurses' residence

\begin{tabular}{|c|c|c|c|c|}
\hline Variables & Urban & Rural & $\mathrm{T}$ & $\mathrm{P}$ \\
\hline \multicolumn{5}{|l|}{ Hindering factors: } \\
\hline Patient related factors & $35.61 \pm 7.08$ & $35.36 \pm 8.80$ & 0.138 & 0.891 \\
\hline Environmental related factors & $31.3 \pm 7.29$ & $31.12 \pm 7.21$ & 0.147 & 0.883 \\
\hline Co-workers related factors & $28.37 \pm 9.77$ & $24.31 \pm 12.22$ & 1.629 & 0.107 \\
\hline $\begin{array}{l}\text { Hospital management and work with } \\
\text { supervisors }\end{array}$ & $46.45 \pm 15.14$ & $41.80 \pm 15.95$ & 1.324 & 0.189 \\
\hline Nursing staff related factors & $21.68 \pm 9.39$ & $20.29 \pm 10.27$ & 0.633 & 0.528 \\
\hline \multicolumn{5}{|l|}{$\begin{array}{l}\text { observational Communication } \\
\text { skills: }\end{array}$} \\
\hline Building therapeutic relationship & $11.11 \pm 3.24$ & $9.40 \pm 3.48$ & 2.254 & $0.027 *$ \\
\hline Open the discussion & $5.97 \pm 2.49$ & $5.60 \pm 2.52$ & 0.675 & 0.502 \\
\hline Gathering information & $23.18 \pm 9.25$ & $22.07 \pm 9.07$ & 0.543 & 0.589 \\
\hline Understanding patients' perspectives & $9.34 \pm 4.33$ & $9.38 \pm 4.56$ & 0.039 & 0.969 \\
\hline Sharing information with patients & $6.05 \pm 3.30$ & $5.76 \pm 3.02$ & 0.411 & 0.382 \\
\hline Reach agreement & $5.94 \pm 3.14$ & $5.90 \pm 2.77$ & 0.064 & 0.949 \\
\hline Providing closure & $8.61 \pm 5.11$ & $8.24 \pm 4.33$ & 0.340 & 0.737 \\
\hline
\end{tabular}

*Significant at $\mathrm{p}$ - value $<0.05$.

T. student's t test 
Table (8) Comparison between both the mean total score of hindering factors and observational nurse's communication skills in relation to nurses' gender

\begin{tabular}{|c|c|c|c|c|}
\hline Variables & Males & Females & $\mathrm{T}$ & $\mathrm{P}$ \\
\hline \multicolumn{5}{|l|}{ Hindering factors: } \\
\hline Patient related factors & $35.89 \pm 7.93$ & $35.26 \pm 8.07$ & 0.329 & 0.743 \\
\hline Environmental related factors & $31.07 \pm 6.98$ & $31.31 \pm 7.38$ & 0.139 & 0.890 \\
\hline Co-workers related factors & $31.30 \pm 9.99$ & $23.66 \pm 11.05$ & 3.016 & $0.003^{*}$ \\
\hline $\begin{array}{l}\text { Hospital management and work with } \\
\text { supervisors }\end{array}$ & $48.96 \pm 15.22$ & $41.48 \pm 15.38$ & 2.058 & $0.043^{*}$ \\
\hline Nursing staff related factors & $23.85 \pm 11.43$ & $19.47 \pm 8.65$ & 1.917 & 0.059 \\
\hline \multicolumn{5}{|l|}{$\begin{array}{l}\text { Observational Communication } \\
\text { skills: }\end{array}$} \\
\hline Building therapeutic relationship & $12.33 \pm 3.12$ & $9.13 \pm 3.08$ & 4.337 & $0.001 *$ \\
\hline Open the discussion & $7.00 \pm 2.73$ & $5.15 \pm 2.13$ & 3.328 & $0.001^{*}$ \\
\hline Gathering information & $27.07 \pm 10.29$ & $20.32 \pm 7.58$ & 3.018 & $0.004 *$ \\
\hline Understanding patients' perspectives & $11.19 \pm 4.42$ & $8.43 \pm 4.17$ & 2.736 & $0.008^{*}$ \\
\hline Sharing information with patients & $7.30 \pm 3.37$ & $5.19 \pm 2.79$ & 2.797 & $0.008^{*}$ \\
\hline Reach agreement & $7.26 \pm 3.45$ & $5.24 \pm 2.40$ & 2.718 & $0.010^{*}$ \\
\hline Providing closure & $10.56+5.59$ & $7.31 \pm 3.77$ & 2.718 & $0.010^{*}$ \\
\hline
\end{tabular}

*Significantat p- value $<0.05$.

T. student's t test

\section{Discussion;}

Communication is the key factor in providing and managing the care of patients with mental illness. Peplau stated that the nurse-patient relationship is the core of mental health nursing and that the behaviors of both nurse and patient interacting together play a significant role in the quality of patient care and its outcomes. Although communication is the foundation of the nurse-patient relationship, psychiatric nurses have been criticized for their lack of interaction and therapeutic engagement with patients (Sharac et al., 2010). ${ }^{(22)}$ This study aims to assess communication problems that face nursing staff during their interaction with hospitalized mentally ill patients in psychiatric hospitals. This study indicates that the factor of patient, environment, organization and nurses can play a decisive role in the effectiveness of this communication.

The result of the present study was considered some factors that hinder communication between the psychiatric nurses and patients. It revealed that, more than half of nurses reported that factors related to psychiatric patient always hindering communication. This may be due to that the patient is slow to response, has an aggressive behavior, pause during speech and the patient suffers from delusions and hallucinations, these symptoms make nurses unable to communicate with psychiatric patients. The previous interpretation was emphasized by a study done by Bowers et al., (2012) described the results of a study regarding experienced nurses in their interactions with patients who exhibited acute mental illness, the behaviors of these patients were challenging and confusing, having perceptual disturbances, delusions and hallucinations, made it difficult for the nurse- patient interaction to occur. ${ }^{(23)}$ In this respect. The result of Ward, L. (2013) shows that inpatient psychiatric units consist of a number of patients who suffer from various types of mental 
illnesses which can be difficult for the nurse to maintain effective communication with such patients. According to Ward (2013), the majority of nurses working in an inpatient psychiatric unit have experienced aggressive or violent behaviors by patients at least once in their career. ${ }^{(24)}$

Erchul et al, 2010 reported that communication with the patient who is admitted with mental health challenge is complex. When the patient is in a crisis, most patients undergo physical or psychological changes. Pain, anxiety or fear can cause patients to deal with their problems differently than they are healthy and in a familiar environment. ${ }^{(25)}$ According to Rose L. Moss(2015) reported that some psychiatric patients on an acute inpatient or long-term psychiatric unit who are diagnosed with major depressive disorder, psychotic disorder, or a personality disorder may experience a severe psychosis, may be severely depressed, may express suicidal or thoughts of self-injury and display aggressive behaviors. These patients need to be maintained in a safe environment. Many psychiatric nurses feel that their ability to communicate, assess, and treat such patients appropriately is inadequate. This creates tension in providing care and hinders the development of the nurse-patient relationship. ${ }^{(26)}$

According to Anderson \& West,(2011) reported that Psychiatric units, whether acute or long-term, experience high levels of conflict or unpredictable behaviors from psychiatric patients have shown increases in physical and psychological injuries with staff. Psychiatric patients' aggressive behaviors have generated high acuity levels causing an unsafe milieu. Aggression by psychiatric patients represents a serious threat to the safety and security of both patients and staff. Work pressure, poor communication skills, stress, and time constraints have all contributed to psychiatric patients' conflict behaviors. ${ }^{(27)}$

The current study showed that, more than half of nurses reported that factor of co-workers strongly hinder nursing- patient communication. This may be due to the problem between them in work due to refusing their criticism or suggestions and there is no collaboration between them on the performance of the job tasks. This can be interpreted that the difference in gender, culture, level of education, knowledge and experience between nurses leads to conflicts and disagreements between them as well as hindering them from interaction with patient. This result is similar to the study of Kelly, J. (2006) which indicated that the conflict among colleagues can have an indirect influence on the therapeutic nurse-client relationship. Poor relationships among members of the health care team negatively affect the delivery of care and communication with patient. ${ }^{(28)}$

In the present study, it was observed that $75 \%$ of nurses reported that factors related to hospital management and work with supervisors strongly hinder nursing- patient communication. This may be explained as too much papers and waste of time, shortage for action and high work load they extend to them lead to stress. This may be due to that the number of nurses is smaller than the number of patient, so the administration work, stress of job and unsatisfying relation with supervisors hinder nurses from communication with patients. In this respect, the study of Kwadwo Ameyaw Korsah (2011) reported that there were human resource factors which undermined effective nurse-client interactions. Staffing shortages lead to nurses who did not have enough time for their clients. Few nurses who were coupled with high workload lead to inadequate interaction with clients. ${ }^{(29)}$ In addition, the study of Vahid Zamanzadeh et al (2014) indicated that organizational dimension; factors such as time, workload, and imbalance between such factors to minimize communication with patients. These findings indicated that the lack of monitoring on communication processes by nursing managers influences the nurse-patient communication.. ${ }^{(30)}$

The present study represented that, the majority of nurses reported that environmental factors always hinder nursing- patient communication. This may be due to that the hospital environment was overcrowded, unclean, presence bad ventilation and the lack of privacy of the place, these factors are considered an important barrier that lead to the nurse and patient not concentrate on the topic of communication. In this aspect the result of 
Neumann et al, 2012 reported that barriers to effective communication can impede or deform the message. There may be physical barriers that often occur due to the environment. Example of this is the lack of time and improper building. The unit allotted for psychiatry was undersized; nurses and the patients were locked in the small unit, where they could not easily listen to each other's conversations. ${ }^{(31)}$ Rose L. Moss 2015 showed that current practice on inpatient psychiatric units has been associated with overcrowded and chaotic environments; high stimulus atmosphere that contributes to escalating behaviors; conflict over patient's course of treatment. (26)

The result of the current study revealed that less than half of nurses reported that the factor related to nurse's problem sometimes hinder communication with patient. This may be due to that the nurses suffer from stigma about mental illness, lack of communication skills and training lead to their negative attitudes and beliefs about mental illness and often hinder communication with patient. In this respect, the study of Mavundia (2009) showed that mental health challenges have a negative influence on nurses ' attitude and patients who have mental health disorders are perceived as dangerous. Such stigmatizations of patient with mental health challenges could interfere with the nurses ability and willingness to facilitate communication or relationship with patient. ${ }^{(32)}$ Therefore, the study of Kwadwo Korsah (2011) indicated that the nurses noted that stress and overwork lead to frustration and anger in the work place. Personal life issues of some nurses affected their interactions and communication with clients. ${ }^{(29)}$ The study of Vythilingum (2009) also recognized that nurses who were not specifically educated and experienced in psychiatric nursing found it difficult to attend to the patients' mental health need and communicate with them. ${ }^{(33)}$

Moreover, the study of Vahid Zamanzadeh et al (2014) indicated that professional and psychological characteristics of the nurses were other influential factors on the nursepatient communication. The lack of holistic perspective among nurses inclined them towards doing physician orders and physical care. ${ }^{(30)}$

In a study of Jordanian nurses conducted by Hamdan-Mansour \& Wardam (2011), 60\% of Jordanian nurses exhibited negative attitudes towards patients with mental illness. It also emphasized that establishing and maintaining appropriate communication can be extremely difficult, especially when nurses perceive mentally ill persons to be "dangerous, immature, dirty, cold hearted, harmful, and pessimistic" . Also, mental health professionals' attitudes about mentally ill patients can impede communication and therefore have implications on the patient's treatment. ${ }^{(34)}$ According to Jacob, J. D., \& Holmes, D. (2013) Who reported that nurses need to build a caring and trustful relationship to enables patients to feel more secure and to help them open up and share their true feelings. ${ }^{(35)}$

The result of this study revealed that there was a statistically significant difference between nurses' age and duration of nurses' experience in relation to hindering factors of communication. Significant differences appear between co-workers factors and nurses' age. This can be interpreted that the younger nurses may have no experience about their roles and responsibilities. So many problems may arise between them and affects their communication with patient.

According to the present study, the result indicated that there was a statistically significant difference between experience in nursing, patient specific and hospital management and work with supervisors. This may be due to that the years of experience and number of training sessions in psychiatric nursing are low so the nurses suffer from difficulties in how to deal with their problem especially with psychiatric patients. Also, the number of nurses is smaller than to number of patient, so heavy work load, stress of job and unsatisfying relation with supervisor hinder nurses from communication with patients.

There was a statistically significant difference between the nurse's age and providing closure in communication skills. This may indicate that the young age of nurses may be a barrier for them because this skill is special value in health communication process because it includes very important skills, about guidance, follow-up or contact arrangements. According to the present study, the result indicated that there was a statistically significant difference between experience in psychiatric nursing and communication skills items including (gathering information, sharing information with 
patients, reach agreement and providing closure). This may be due to that the nurses suffer from inadequate knowledge and training of communication skills and use it with psychiatric patient but working with psychiatric patient needs communication skills, so, the nurses complain from how to deal with them.

The present finding showed that there was a statistically significant difference between nurses' residence and building therapeutic relationship in communication skills. This may indicate that the difference in culture and belief between nurses and patient and the distance between the hospital and their residence may hinder building the therapeutic relationship between nurses and patients. In conclusion, nurses may commit errors but practice can make them perfect; especially, in a skill like communication. Thus, nurses must practice as much as possible and try reducing communication errors. As discussed, there are several causes and effects of poor communication; especially, in psychiatric nursing. But nurses should use themselves as a therapeutic instrument, so that they can help the psychiatric patients for their early recovery. ${ }^{(36)}$

\section{Conclusion;}

According to the findings of the present study, it can be concluded that all nursing staff facing problems during their interaction with hospitalized mental ill patients in psychiatric hospitals but with various degrees. It was found that their problem was related to many factors such as patient, environment, organization and nurses' problems, the most common factors were related to patient and environment that hinder communication. Also, it can be concluded that all nursing staff experience difficulties in communication skills but with various degrees, more than half of them having weak scores in communication skills.

\section{Recommendations;}

Based on the results of this study, the following recommendations are suggested. -Even the best nurse communicators need support in order to be effective, Practical measures are necessary such as having sufficient time and psychological support.

- Practical supports are needed to foster and maintain effective communication in order to promote effective nurse-patient communication.

-Conducting workshops and holding seminars to help the nurses refresh their knowledge and discuss their daily problems facing them in work place.

-Training programs are needed to be designed for hospital staff about effective communication and self-awareness to improve their interaction with patients.

-Nursing staff need to be integrated in educational programs about communication skills. Enhancing the therapeutic nurse -patient relationship to avoid their daily problem when communicate with patient.

-There is a need for further researches regarding barriers that hinder nursing staff from communication with patients

\section{Reference}

1-Shellal \&Vidbeck: Psychiatric Mental Health Nursing: $5^{\text {th }}$ ed. Com, Willams,wolters lippincott.2011; 99-117.

2- Moyle W: Nurse -Patient Relationship, A dichotomy of Expectations, International Journal of Mental Health Nurse, 2003; 12(2). $103-09$.

3- Lachine O.A:Effect of Using Transactional Analysis in Group Training for Teaching Staff on Their Relationship with Student. Unpublished Master Thesis. High Institute of Nursing. University of Alexandria,1992. 
4- Balzer-Riley t : Communication in Nursing ,Communication Assertively, Responsibly in Nursing : Aguide Book . Com, St . Louis. Mosby, 1996; 14-17.

5- Arnold E\& Boggsk : Interpersonal Relationship , Professional Communication Skills for Nurses , $5^{\text {th }}$ ed, Com ., Louis , Saunders, $2007 ; 311-313$.

6- Schirmer J. „Mauksch L .,Lang F.,Marvel K., Zoppi „Epstein R., Brock D\& Pryzbylski M: Assessing Communication Competence: A Review of Current Tools, Medical Student Education and Family Medicine.2005; 37(3).184-192.

7- Cook R. t., Render $m$ \& Awoods D.P: Gaps in the continuity of Care and progress on patient safety, British Medical Journal , (2000) ; 320: 791- 794.

8- Shives L. R: Basic Concepts of Psychiatric Mental Health Nursings,5 thed, Com ., Philadelphia , Lippincott, 2002; 41-49 .

9-Nikendei C., Bosse H.M., Hoffmann K., Moltner A., Hancke R \& Conrad C., : Outcome of Parent-Physician Communication Skills Training for Pediatric Residents. Patient Education and Counseling. Iranin Journal of Nursing and Midwifery, 2011;82(1):94-9.

10-Chiovitti R.F: Nurses' Meaning of Caring With Patients in Acute Psychiatric Hospital Settings: A Grounded Theory Study. International Journal of Nursing Studies. 2008;45(2):203-23.

11-Bylund C.L., Brown R.F., Ciccone B.L., Levin T.T., Gueguen J.A., Hill C \& Kissane D.W: Training Faculty to Facilitate Communication Skills Training: Development and Evaluation of A workshop, Patient Education and Counseling. Iranin Journal of Nursing and Midwifery, 2008;70(3):430-6.

12-Shattell M.M., McAllister S., Hogan B \& Thomas S.P: "She Took The Time to Make Sure She Understood": Mental Health Patients Experiences of Being Understood. Journal of Psychiatry Nurses , 2006;20(5):234-41.

13-Jones A: Nurse Talking to Patient: Exploring Conversation Analysis as Amean of Researching Nurse - Patient Communication, International Journal of Nursing Studies .2003; 40 (6):609-18.

14-Oandasan I .,Baker G.R \& Barker K: Teamwork in Healthcare: Promoting Effective Teamwork in Healthcare in Canada Canadian Health Research Foundation June 2006; 8590.

15-Mohr W: Psychiatric Mental Health Nursing $7^{\text {th }}$ ed com ., Philadelphia Lippincott.2009; 188-189.

16-CeccioT .F. A\& ceccio C .M: Effective communication in Nursing : Theory and Practice Journal of Advanced Nursing . 1999; 29-1921 -1426.

17-Worren B T:Cultural Competence Abest Practice Process for Psychiatric Mmental Health Nursing . Journal of the American Psychiatric Nurses Association ,2000; 112: 35

18-Fakhoury W.K\& Wright D: Communication and Information Needs of A random Sample of Community Psychiatric Nurses in the United Kingdom. Journal of Advanced Nursing. 2000;32(4):871-80.

19-Edwards N., Peterson W.E \& Davies B.L: Evaluation of a Multiple Component Intervention to Support the Implementation of a 'Therapeutic Relationships' Best Practice Guideline on Nurses' Communication Skills. Patient Education and Counseling. Iranin Journal of Nursing and Midwifery, 2006;63(1-2):3-11. 
20-Heaven C., Clegg J\& Maguire P: Transfer of Communication Skills Training from Workshop to Workplace: the Impact of Clinical Supervision. Patient Education and Counseling. Iranin Journal of Nursing and Midwifery, 2006;60(3):313-25.

21-Fetzer B G: Conference on Physician- Patient Communication in Medical Education: Communication checklist: The Kalamazoo Consensus Statement Academic Medicine 2001; 76 (4): $-390-393$.

22- Sharac, J., McCrone, P., Sabes-Figuera, R., Csipke, E., Wood, A., \&Wykes, T. Nurse and Patient Activities and Interaction on Psychiatric In Patients Wards: a Literature Review. International Journal of Nursing Studies, 47(7), 2010; 909-917.

23-Bowers, L., Brennan, G., Winship, G., \&Theodoridou, C. How Expert Nurses Communicate with Acutely Psychotic Patients. Mental Health Practice, 2012 13(7), 24-26.

24-Ward, L. Ready, Aim Fire! Mental Health Nurses under Siege in Acute Inpatient Facilities. Issues in Mental Health Nursing, 2013 34(4), $281-87$.

25-Erchul, W.P\&Martens,K. Caplan's Preventive Model. School Consultation; Conceptual and Empirical Bases of Practice. $3^{\text {rd }}$ Ed. Springersny.2014 Chapter 5. 33; 90.

26-Rose L. Moss. Communication Skills of Novice Psychiatric Nurses with Aggressive Psychiatric Patients (Doctor Thesis)College of Health Sciences Walden University; 2015.

27-Anderson, A., \& West, S. G. Violence against mental health professionals: When the treater becomes the victim. Innovation in Clinical Neuroscience, 2013 8(3), 34-39. Retrieved from http://www.ncbi.nlm.nih.gov/pmc/articles/PMC3074201

28- Kelly, J. An overview of conflict. Dimensions of Critical Care Nursing, 2009 25(1), 22-28.

29-Kwadwo Ameyaw Korsah.Nurses' stories about their interactions with patients at the Holy Family Hospital, Techiman, Ghana Open Journal of Nursing, 2011, 1, 1-9.

30- vahidZamanzadeh et al. Factors Influencing Communication between the Patients and their Nurses Indian. Journal of Palliative Care, 2014 Jan-Apr; 20(1): 12-20.

31-Neumann et al. poor nurse patient communication in mental health setting nursing essay. http://www.ukessays.com/essays/nursing/.php\#ixzz3IGAfvHxu Copyright @ 2012.

32 -Mavundia,T.R. Professional Nurses Perception of Nursing Mentally Ill People in a General Hospital Setting. Journal of Advanced nursing; 2009,32(6)1569-1578, Available from http:// o-web.ebscohost. Com. utlink. At. Ac. Za/ ehost/ results vid pdf(Accessed10 Jun2009).

33-Vgthilinyum, B. Anxiety Disorder in Pregnancy and the Postnatal Period. Continuing Medical Education. 2009; 27(10); 450-452

34-Hamdan-Mansour, A. M., \&Wardam, L. A. Attitudes of Jordanian Mental Health Nurses Toward Mental Illness and Patients with Mental Illness. Issues in Mental Health Nursing, 2011; 30(11), 705-711.

35-Jacob, J. D., \& Holmes, D: Working under Threat: Fear and Nurse-Patient Interactions in a Forensic Psychiatric Setting. Journal of Forensic Nursing, 2013; 7(2), 68-77.

36-Hem \&Heggen. Poor Nurse Patient Communication in Mental Health Setting Available-at:http://www.ukessays.com/essays/nursing/poor-nurse-patient-communicationin-mental-health-setting-nursing-essay.php\#ixzz3IGBqKBuQ; 2015. 